\title{
Corneal ectasia after myopic laser in situ keratomileusis: a long-term study
}

This article was published in the following Dove Press journal:

Clinical Ophthalmology

31 October 2012

Number of times this article has been viewed

\section{Leopoldo Spadea' \\ Emilia Cantera ${ }^{2}$ \\ Magdalena Cortes ${ }^{2}$ \\ Nicole Evangelista \\ Conocchia' \\ Charles WM Stewart' \\ 'University of L'Aquila, Department of Biotechnological and Applied Clinical Sciences, Eye Clinic, L'Aquila, ${ }^{2}$ Villa Stuart Clinic, Department of Ophthalmic Sciences, Rome, Italy}

Correspondence: Leopoldo Spadea Via Benozzo Gozzoli 34, 00142 Rome, Italy

Tel +3908623 | 967|

Fax +3908 623। 964।

Email Ispadea@cc.univaq.it
Background: The purpose of this study was to evaluate the long-term postoperative incidence of and key factors in the genesis of corneal ectasia after myopic laser-assisted in situ keratomileusis (LASIK) in a large number of cases.

Methods: A retrospective review of one surgeon's myopic LASIK database was performed. Patients were stratified into two groups based on date of surgery, ie, group 1 (1313 eyes) from 1999 to 2001 and group 2 (2714 eyes) from 2001 to 2003. Visual acuity, refraction, pachymetry, and corneal topography data were available for each patient from examinations performed both before and after the refractive procedures.

Results: Of the 4027 surgically treated eyes, 23 (0.57\%) developed keratectasia during the follow-up period, which was a minimum seven years; nine eyes $(0.69 \%)$ were from group 1 and 14 eyes $(0.51 \%)$ were from group 2 . The onset of corneal ectasia was at $2.57 \pm 1.04$ (range 1-4) years and $2.64 \pm 1.29$ (range 0.5-5) years, respectively, for groups 1 and 2. The most important preoperative risk factors using the Randleman Ectasia Risk Score System were manifest refractive spherical error in group 1 and a thin residual stromal bed in group 2. Each of the cases that developed corneal ectasia had risk factors that were identified.

Conclusion: Ectasia was an uncommon outcome after an otherwise uncomplicated laser in situ keratomileusis procedure. The variables present in eyes developing postoperative LASIK ectasia can be better understood using the Randleman Ectasia Risk Score System.

Keywords: corneal topography, Ectasia Risk Score System, keratectasia, myopia, LASIK

\section{Introduction}

Laser in situ keratomileusis (LASIK) is one of the most widely used methods for correction of refractive errors. Preserved integrity of the superficial corneal layers after LASIK ensures minimal tissue proliferation, resulting in a clear cornea and fast recovery time. However, some complications have been described in the literature. One of the most troublesome complications after LASIK is progressive iatrogenic keratectasia, which can occur up to several months after surgery. ${ }^{1}$ Although the actual incidence of ectasia is unknown, it has been estimated to be $0.04 \%-0.6 \%{ }^{2-4}$ Several risk factors have been suggested in an attempt to avoid ectasia. ${ }^{5,6}$ However, controversy exists as to the predictability of these factors, and some cases continue to occur without a clear etiological explanation. ${ }^{2,7}$ Ideally, patients at risk of ectasia would be identified prior to laser surgery and be classified as unsuitable candidates for LASIK; however, at present, there is no absolute test, system, or marker that can identify patients at risk of developing ectasia.

Randleman et al recently designed the Ectasia Risk Score System, which is a method of preoperative screening based upon use of risk scales and identification 
of a number of preoperative parameters that may be associated with increased risk of ectasia. ${ }^{8}$ The most common risk factors, in order of significance, include: abnormal preoperative corneal topography, low residual stromal bed thickness, young age, thin preoperative corneal thickness, and higher attempted refractive correction. These factors are then amalgamated into a risk scale. However, this risk factor scale may miss a significant proportion of patients at risk of ectasia because other factors also play a role in the risk of ectasia. ${ }^{9-11}$

The purpose of this study was to evaluate the long-term postoperative incidence of and key factors in the genesis of corneal ectasia after myopic LASIK in a large number of cases.

\section{Materials and methods}

This retrospective study included the records of all patients (4027 eyes) who underwent LASIK surgery performed by the same surgeon (Italo Cantera, Quisisana Clinic, Rome, Italy) between March 1999 and March 2003. All patients signed an informed consent in accordance with the tenets of the Declaration of Helsinki. Data points analyzed included preoperative uncorrected visual acuity, best spectacle-corrected visual acuity, treated manifest refractive spherical equivalent, and details of excimer laser ablation. Corneal topography and corneal thickness were analyzed using tomography (Orbscan, Bausch and Lomb Inc, Rochester, NY), computerized videokeratoscopy (Keratron, Optikon 2000, Rome, Italy, and Eye Top, CSO, Florence, Italy). Four keratoscopic images were obtained from each eye using each topographic instrument, and the best one was chosen. Keratometric astigmatism was defined as the refractive curvature difference at the $3 \mathrm{~mm}$ diameter. Corneal thickness was evaluated using ultrasound pachymetry (Tomey, Nagoya, Japan).

On the basis of the date of surgery and the specific surgical equipment used, the 4027 eyes were separated into two groups. Group 1 (1313 eyes) underwent LASIK between March 1999 and March 2001, with two men and four women developing ectasia. The preoperative data are summarized in Table 1. Preoperative topographic corneal maps appeared quite normal, with no evidence of underlying or forme fruste keratoconus (Figure 1). LASIK was performed using topical anesthesia (oxybuprocaine $0.4 \%$ eye drops). Nasal-hinged corneal flaps, planned as $120 \mu \mathrm{m}$ thick and $8.5 \mathrm{~mm}$ diameter were created with a manually guided microkeratome (MDSC,

Table I Demographics and preoperative characteristics of the two patient groups

\begin{tabular}{|c|c|c|c|}
\hline & $\begin{array}{l}\text { Overall } \\
\text { (2004 patients, } 4027 \text { eyes) }\end{array}$ & $\begin{array}{l}\text { Group I } \\
\text { (663 patients, } 1313 \text { eyes) }\end{array}$ & $\begin{array}{l}\text { Group } 2 \\
\text { (134I patients, } 2714 \text { eyes) }\end{array}$ \\
\hline \multicolumn{4}{|l|}{ Age (years) } \\
\hline Mean \pm SD & $31.6 \pm 8.45$ & $27.9 \pm 9.55$ & $35.7 \pm 7.25$ \\
\hline Range & 22,48 & 25,33 & 22,48 \\
\hline \multicolumn{4}{|l|}{ CDVA (decimal) } \\
\hline Mean \pm SD & $0.7 \pm 0.27$ & $0.7 \pm 0.25$ & $0.8 \pm 0.25$ \\
\hline Range & $0.3,1.0$ & $0.3,0.9$ & $0.3,1.0$ \\
\hline \multicolumn{4}{|l|}{ MRSE (D) } \\
\hline Mean \pm SD & $-8.11 \pm 4.48$ & $-14.83 \pm 4.12$ & $-5.32 \pm 2.85$ \\
\hline Range & $-1.62,-21.12$ & $-7.50,-21.12$ & $-1.62,-13.00$ \\
\hline \multicolumn{4}{|l|}{ Average Sim K (D) } \\
\hline Mean \pm SD & $42.38 \pm 2.06$ & $42.65 \pm 1.99$ & $42.07 \pm 1.90$ \\
\hline Range & $40.2,46.0$ & $40.2,46.0$ & $40.6,45.6$ \\
\hline \multicolumn{4}{|c|}{ Corneal thickness $(\mu \mathrm{m})$} \\
\hline Mean \pm SD & $541.32 \pm 34.6$ & $521.22 \pm 24.1$ & $549.27 \pm 37.4$ \\
\hline Range & 480,631 & 480,556 & 505,631 \\
\hline \multicolumn{4}{|l|}{ IOP $(\mathrm{mmHg})$} \\
\hline Mean \pm SD & $15 \pm 1.72$ & $15 \pm 0.78$ & $14 \pm 1.69$ \\
\hline Range & 10,20 & 11,18 & 10,20 \\
\hline \multicolumn{4}{|l|}{ ECD (cells $\left./ \mathrm{mm}^{2}\right)$} \\
\hline Mean \pm SD & $2169 \pm 103$ & $2276 \pm 103$ & $2183 \pm 109$ \\
\hline Range & 2028,2386 & 2037,2386 & 2028,2301 \\
\hline Eyes with ectasia & $23(0.57 \%)$ & $9(0.69 \%)$ & 14 (0.5I\%) \\
\hline \multicolumn{4}{|c|}{ Onset of corneal ectasia (years) } \\
\hline Mean \pm SD & $2.6 \mathrm{I} \pm 1.17$ & $2.57 \pm 1.04$ & $2.64 \pm 1.29$ \\
\hline Range & $0.5,5$ & I, 4 & $0.5,5$ \\
\hline
\end{tabular}

Abbreviations: CDVA, corrected distance visual acuity; MRSE, manifest refractive spherical equivalent; AveSimK, average of simulated keratometry values; IOP, intraocular pressure; ECD, endothelial cell density; SD, standard deviation. 


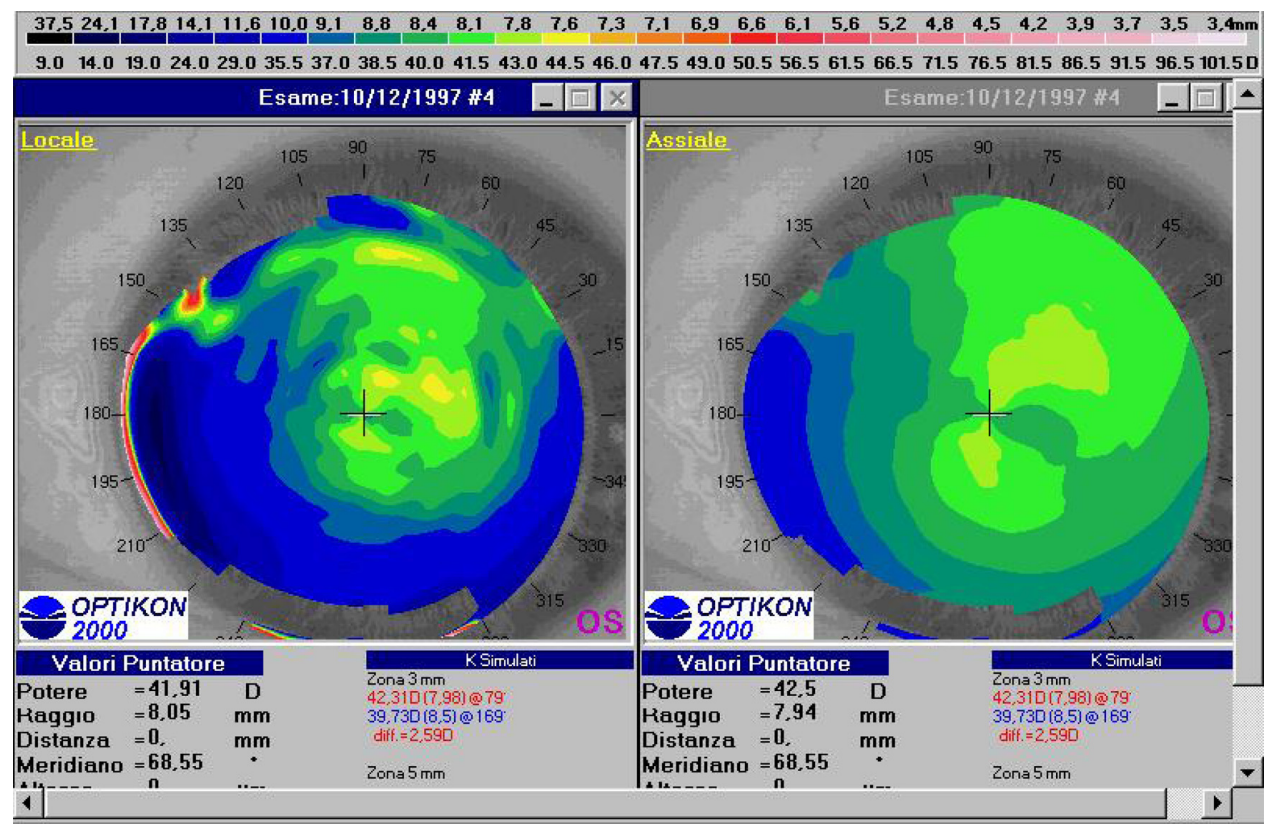

Figure I Preoperative topographic corneal map of a 26-year old female patient (DPL) in group I. Absolute scale, left tangential map, right axial map (Keratron Scout, Optikon 2000).

Abbreviation: SIM K, simulated keratometry value.

Moria, Antony, France). An argon fluoride excimer laser (Apex Plus, Summit Technology, Waltham, MA) was used to carry out the ablations on dry stroma, with a multizonemultipass technique $(3.5 \mathrm{~mm}, 5 \mathrm{~mm}, 6.5 \mathrm{~mm})$ in each eye. The laser treatments were delivered at a wavelength of $193 \mathrm{~nm}$, constant energy frequency of $10 \mathrm{~Hz}, 180 \mathrm{~mJ} / \mathrm{cm}^{2}$ fluence, and an $0.25 \mu \mathrm{m}$ ablation rate. The mean attempted refractive correction was $-14.11 \pm 4.64 \mathrm{D}$ (range -7.50 to $-21.12 \mathrm{D}$ ). The mean estimated ablation depth was $127 \pm 24 \mu \mathrm{m}$ (range $85-156 \mu \mathrm{m}$ ), with a mean planned residual corneal bed of $267 \pm 20 \mu \mathrm{m}$ (range $240-300 \mu \mathrm{m}$ ). At the end of photoablation, the corneal flap was repositioned in place without the aid of sutures. Intraoperative pachymetry was not performed, and an accurate estimation of actual flap thickness was missing for all patients.

Group 2 (2714 eyes) underwent LASIK between March 2001 and March 2003, with six men and four women developing ectasia. The preoperative data are summarized in Table 1. Preoperative videokeratography showed a normal corneal pattern, with no evidence of underlying or forme fruste keratoconus (Figures 2 and 3). In this group, a superior hinged corneal flap $9.5 \mathrm{~mm}$ in diameter was created using an automated microkeratome (Hansatome, Bausch and Lomb Inc, Irvine, CA) with a $160 \mu \mathrm{m}$ plate and a $9.5 \mathrm{~mm}$ suction ring. An argon fluoride excimer laser (Technolas 217, Bausch and Lomb) was used to carry out the ablation on dry stroma using the Planoscan algorithm. The laser treatment was delivered as follows: $193 \mathrm{~nm}$ wavelength, constant energy at $50 \mathrm{~Hz}, 180 \mathrm{~mJ} / \mathrm{cm}^{2}$ fluence, and an $0.25 \mu \mathrm{m}$ ablation rate. The mean attempted correction was $-5.48 \pm 2.88 \mathrm{D}$ (range -2.25 to $-13.50 \mathrm{D}$ ), with an average optical zone of $6.17 \pm 0.7 \mathrm{~mm}$. The mean estimated ablation depth was $131 \pm 43 \mu \mathrm{m}$ (range 93-224 $\mu \mathrm{m}$ ), with a mean residual stromal bed of $258 \pm 23 \mu \mathrm{m}$ (range $240-288 \mu \mathrm{m}$ ). Intraoperative pachymetry was performed in this group, and the mean value of the residual stromal bed was obtained from three intraoperative central corneal measures. At the end of photoablation, the corneal flaps were placed back into position without the aid of sutures.

\section{Results}

All patients included in this study had a minimum of 7 years of follow-up. There were no complications during surgery in any of the patients. All corneas were clear on the first postoperative day, and there were no cases of corneal vascularization or infection. Twenty-three eyes $(0.57 \%)$ developed keratectasia during follow-up, as diagnosed by slit-lamp observation of corneal thinning in the treated area, unstable topographical steepening, and a posterior corneal bulge (Figures 4-6). In most cases, this keratectasia was characterized by progressive steepening of corneal curvature inferiorly or centrally, progressive and significant increases in myopia, with or without increasing astigmatism, an associated severe decrease in uncorrected and often best-corrected visual acuity, and a progressive thinning of the cornea. 


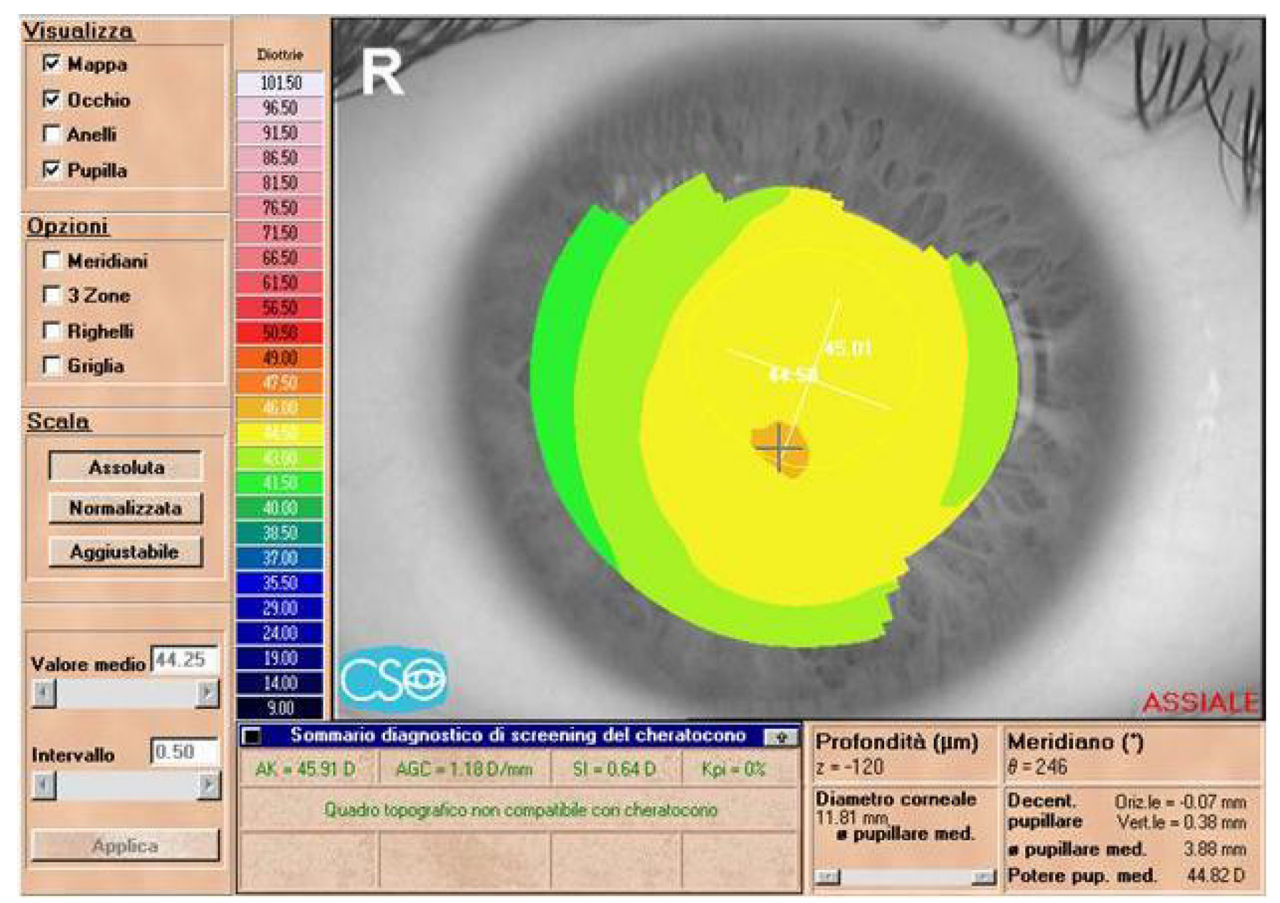

Figure 2 Preoperative topographic corneal map of a 22-year-old male patient (MG) in group 2 (Eye Top, CSO, absolute scale, axial map). Abbreviation: SIM K, simulated keratometry value.

In group 1 , nine eyes $(0.69 \%)$ from six patients developed keratectasia (Table 2). The mean age of the affected patients (four men and two women) was 27 (range 25-33) years. Onset of corneal ectasia appeared at $2.57 \pm 1.04$ (range 1-4) years after LASIK. Videokeratoscopic images showed characteristic central or inferior corneal steepening that progressively and rapidly increased in extension and in dioptric power. Corneal thinning in the treated center area with a steepening and posterior corneal bulge was evident on tomographic examination. Mean postoperative

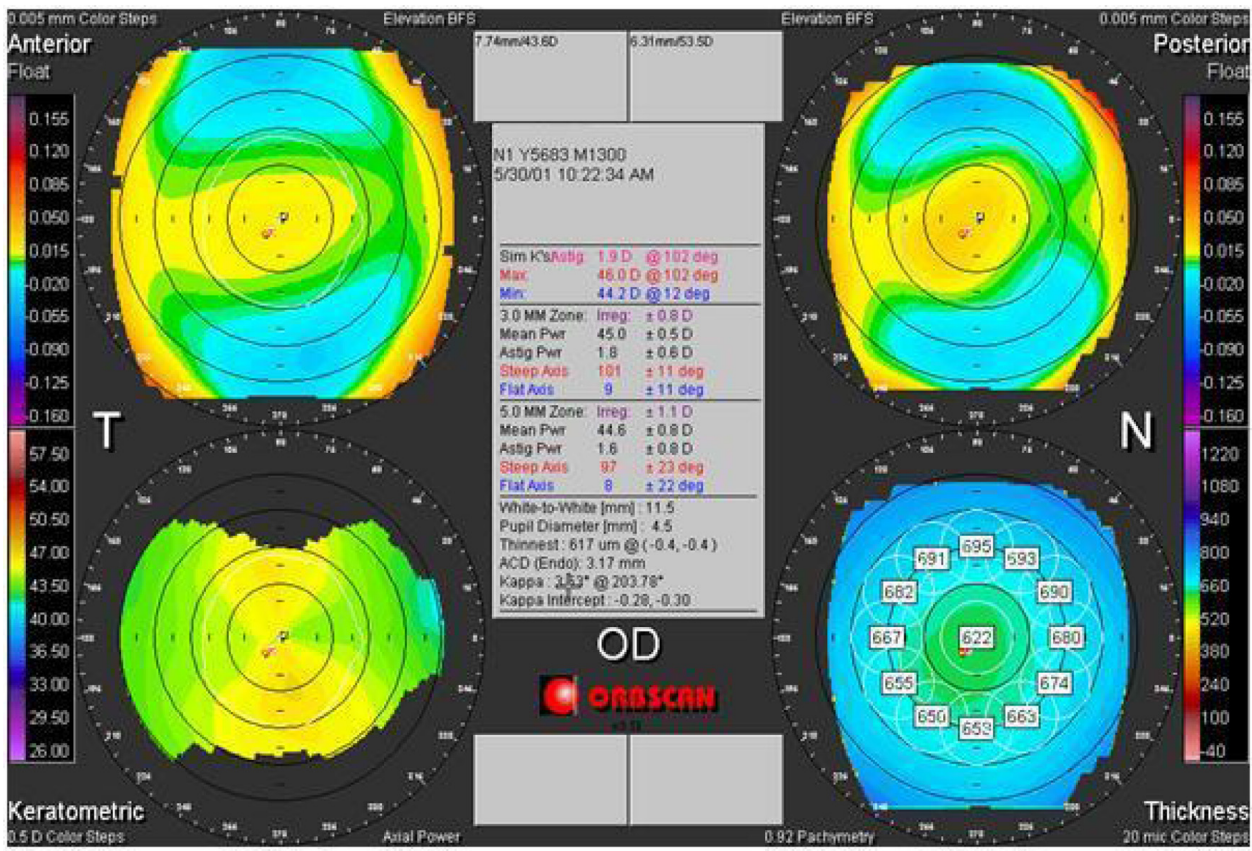

Figure 3 Preoperative tomographic corneal map of a 32-year old male patient (DEE) in group 2.

Note: Top left anterior elevation map, top right posterior elevation map, bottom left axial map, bottom right pachymetric map (Orbscan, Bausch and Lomb). 


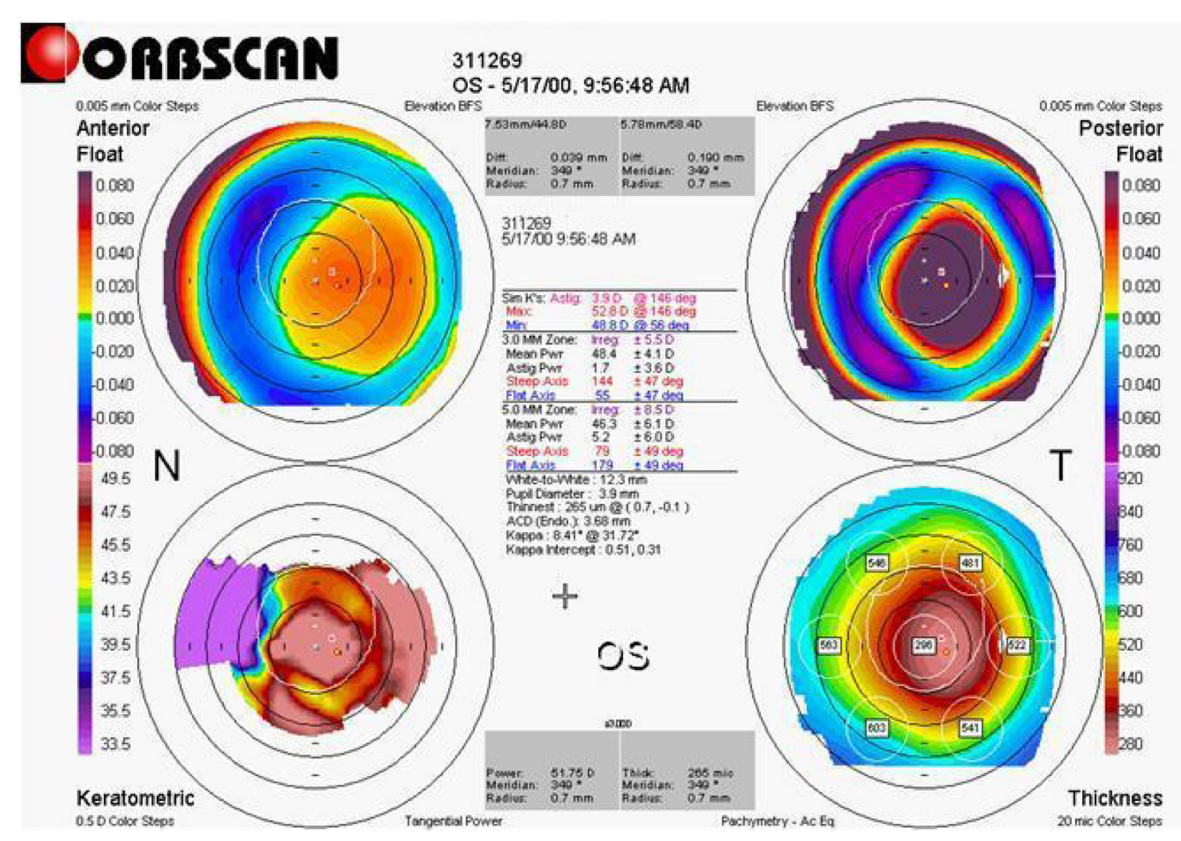

Figure 4 Three-year postoperative topographic corneal map of a patient (DPL) from group I.

Notes: A corneal thinning in the center treated area, with a steepening and a posterior corneal bulge is evidenced. Top left anterior elevation map, top right posterior elevation map, bottom left axial map, bottom right pachymetric map (Orbscan, Bausch and Lomb).

corrected distance visual acuity at the last visit was 20/50, with a mean manifest refractive spherical equivalent of $-10.62 \pm 5.45 \mathrm{D}$ (range -1.25 to $-16.25 \mathrm{D}$ ). Management of post-LASIK ectasia consisted of penetrating keratoplasty for eight eyes and contact lenses or spectacles for the remaining eye.
In group 2, 14 eyes $(0.51 \%)$ from 10 patients developed keratectasia (Table 3 ). The onset of corneal ectasia appeared to be $2.64 \pm 1.29$ (range $0.5-5$ ) years, again with a postoperative topographic pattern of central or inferior corneal steepening that progressively and rapidly increased in extension and in dioptric power. Corneal thinning in the

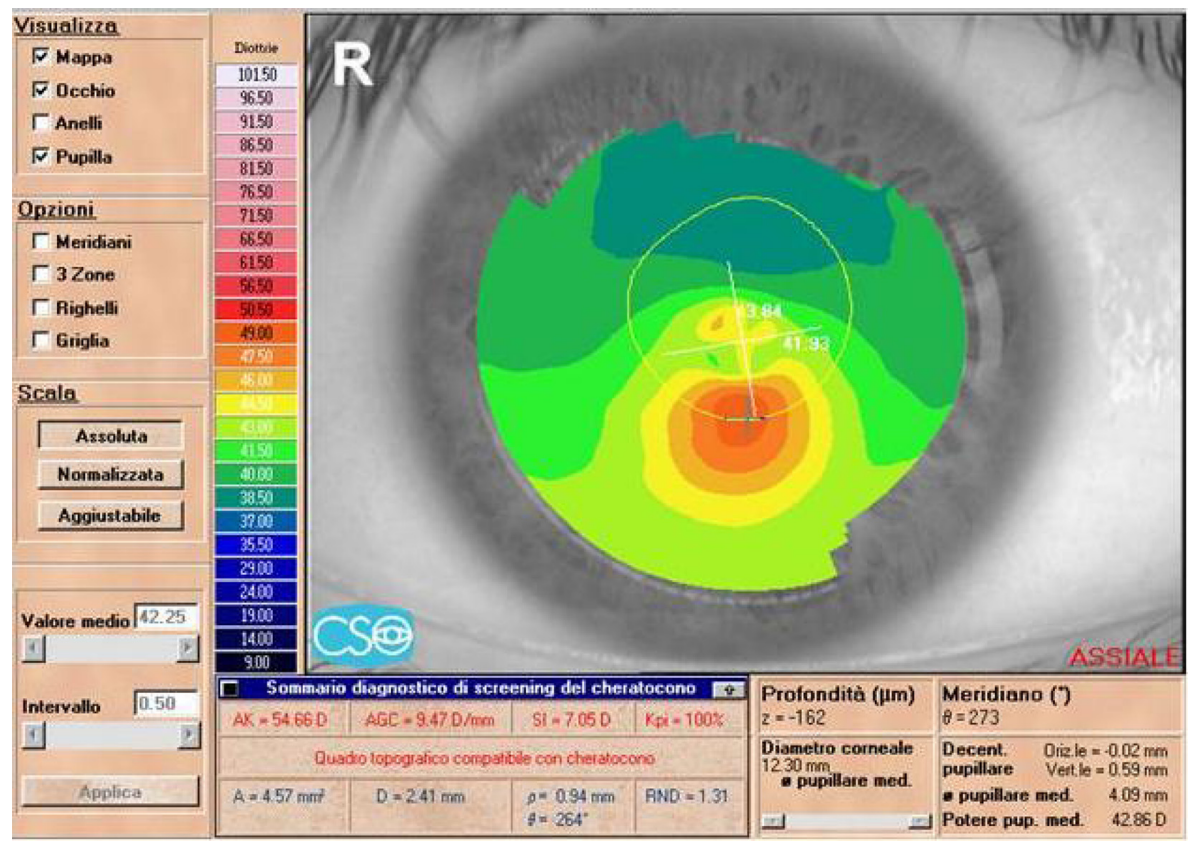

Figure 5 Eighteen-month postoperative topographic corneal map of patient (MG) from group 2.

Note: An inferior corneal steepening is evidenced (Eye Top, CSO, absolute scale, axial map).

Abbreviation: SIM K, simulated keratometry value. 


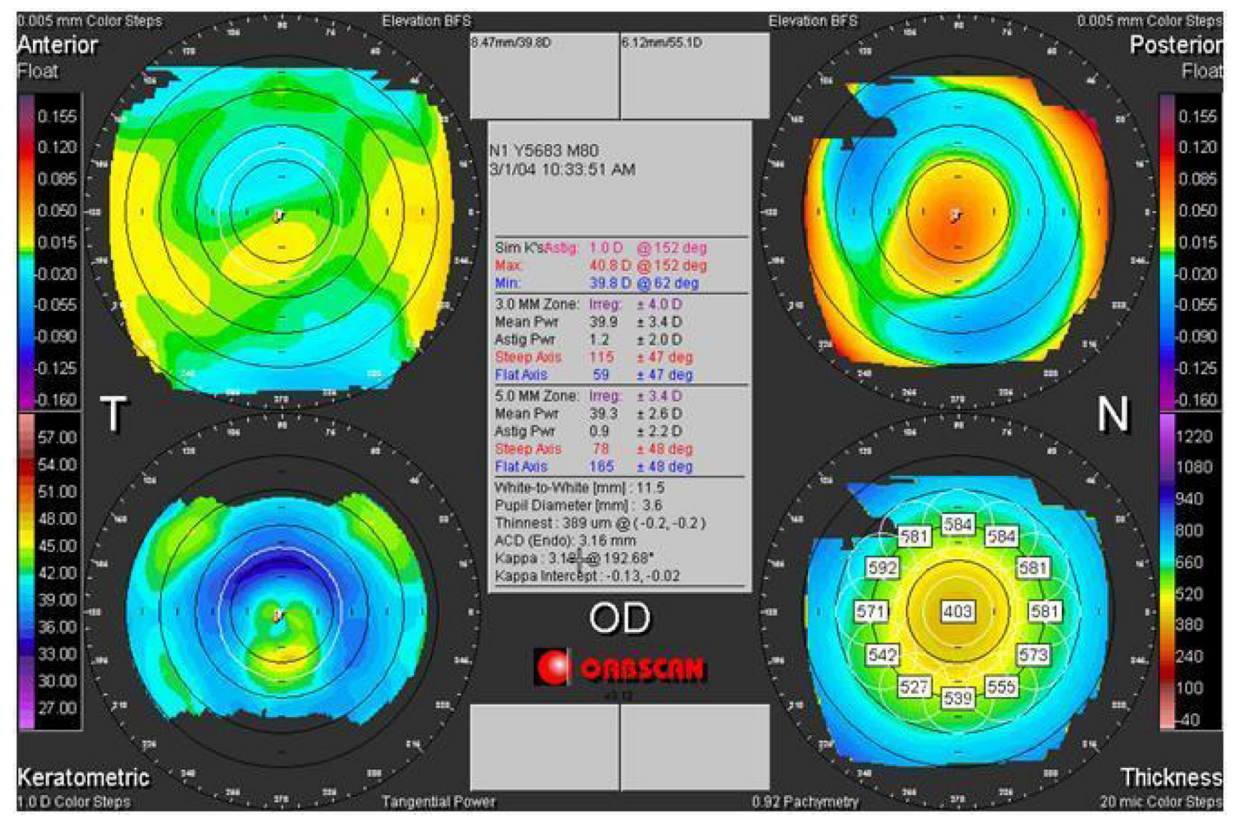

Figure 6 Two-year postoperative tomographic corneal map of a patient (DEE) from group 2.

Notes: A corneal thinning in the treated center area, with a steepening and posterior corneal bulge evident. Top left anterior elevation map, top right posterior elevation map, bottom left axial map, bottom right pachymetric map (Orbscan, Bausch and Lomb).

central treated area with a steepening and posterior corneal bulge was evident on tomographic examination. The mean final postoperative corrected distance visual acuity was 20/30 with a mean manifest refractive spherical equivalent of $1.35 \pm 1.90 \mathrm{D}$ (range -1.25 to $-6.50 \mathrm{D}$ ). Management of post-LASIK ectasia consisted of hard contact lenses or spectacles. None of the affected patients in group 2 required penetrating keratoplasty.

All patients who showed keratectasia were examined retrospectively using the Randleman Ectasia Risk Score System. Of the 23 eyes analyzed, 16 were in the high-risk category, three were in the moderate-risk category, and four

Table 2 Preoperative patient characteristics in group I

\begin{tabular}{|c|c|c|c|c|c|c|c|c|c|}
\hline Patient eye & DPL re & DPL le & GE re & GE le & CA re & RA le & MA re & MA le & $\mathrm{Cl}$ re \\
\hline Age & 26 & 26 & 43 & 43 & 44 & 33 & 49 & 49 & 43 \\
\hline Gender & $\mathrm{F}$ & $\mathrm{F}$ & $\mathrm{F}$ & $\mathrm{F}$ & $M$ & $M$ & $M$ & $M$ & M \\
\hline Preop refraction & $\begin{array}{l}-7= \\
-5\left(20^{\circ}\right)\end{array}$ & $\begin{array}{l}-11.5= \\
-5\left(160^{\circ}\right)\end{array}$ & $\begin{array}{l}-15= \\
-1\left(20^{\circ}\right)\end{array}$ & $\begin{array}{l}-14.75= \\
-1.75\left(20^{\circ}\right)\end{array}$ & $\begin{array}{l}-13= \\
-0.5\left(10^{\circ}\right)\end{array}$ & $\begin{array}{l}-21= \\
-0.25\left(160^{\circ}\right)\end{array}$ & -18.5 & -18.5 & -7.5 \\
\hline Preop BSCVA & 0.6 & 0.6 & 0.8 & 0.8 & 0.6 & 0.6 & 0.5 & 0.5 & I \\
\hline $\begin{array}{l}\text { Preop pachymetry } \\
(\mu \mathrm{m})\end{array}$ & 480 & 493 & 536 & 531 & 527 & 503 & 550 & 556 & 515 \\
\hline Preop & 44.31 & 42.31 & 43.51 & 45 & 44.53 & 45.02 & 44.32 & 44.98 & 42.35 \\
\hline $\operatorname{Sim} K(D)$ & 40.17 & 39.73 & 44.02 & 43.25 & 42.13 & 44.76 & 44 & 44.79 & 41.29 \\
\hline $\begin{array}{l}\text { Preop topography } \\
\text { pattern }\end{array}$ & Normal & Normal & ABT & ABT & Normal & Normal & Normal & Normal & Normal \\
\hline $\begin{array}{l}\text { Laser } \\
\text { correction (D) }\end{array}$ & -7.5 & -12 & -15 & -15 & -13 & -21 & -18 & -18 & -7.5 \\
\hline Optic zone & Multizone & Multizone & Multizone & Multizone & Multizone & Multizone & Multizone & Multizone & Multizone \\
\hline$(\mathrm{mm})$ & $3.5-6.5$ & $3.5-6.5$ & $3.5-6.5$ & $3.5-6.5$ & $3.5-6.5$ & $3.5-6.5$ & $3.5-6.5$ & $3.5-6.5$ & $3.5-6.5$ \\
\hline $\begin{array}{l}\text { Ablation } \\
\text { depth }(\mu \mathrm{m})\end{array}$ & 114 & 126 & 150 & 154 & 114 & 101 & 156 & 147 & 85 \\
\hline $\begin{array}{l}\text { Residual stromal } \\
\text { bed }(\mu \mathrm{m})\end{array}$ & 240 & 240 & 266 & 257 & 293 & 282 & 274 & 289 & 300 \\
\hline ERSS & $\mathrm{HR}$ & HR & $\mathrm{HR}$ & $\mathrm{HR}$ & HR & $\mathrm{HR}$ & HR & $\mathrm{HR}$ & LR \\
\hline
\end{tabular}

Note: Preoperative parameters that may be associated with increased risk of ectasia following the Ectasia Risk Score System are in bold font.

Abbreviations: Preop, preoperative; BSCVA, best spectacle-corrected visual acuity; Sim K, simulated keratometry (D); ABT, abnormal topography pattern; ERSS, Ectasia Risk Score System value (HR, high risk; LR, low risk). 


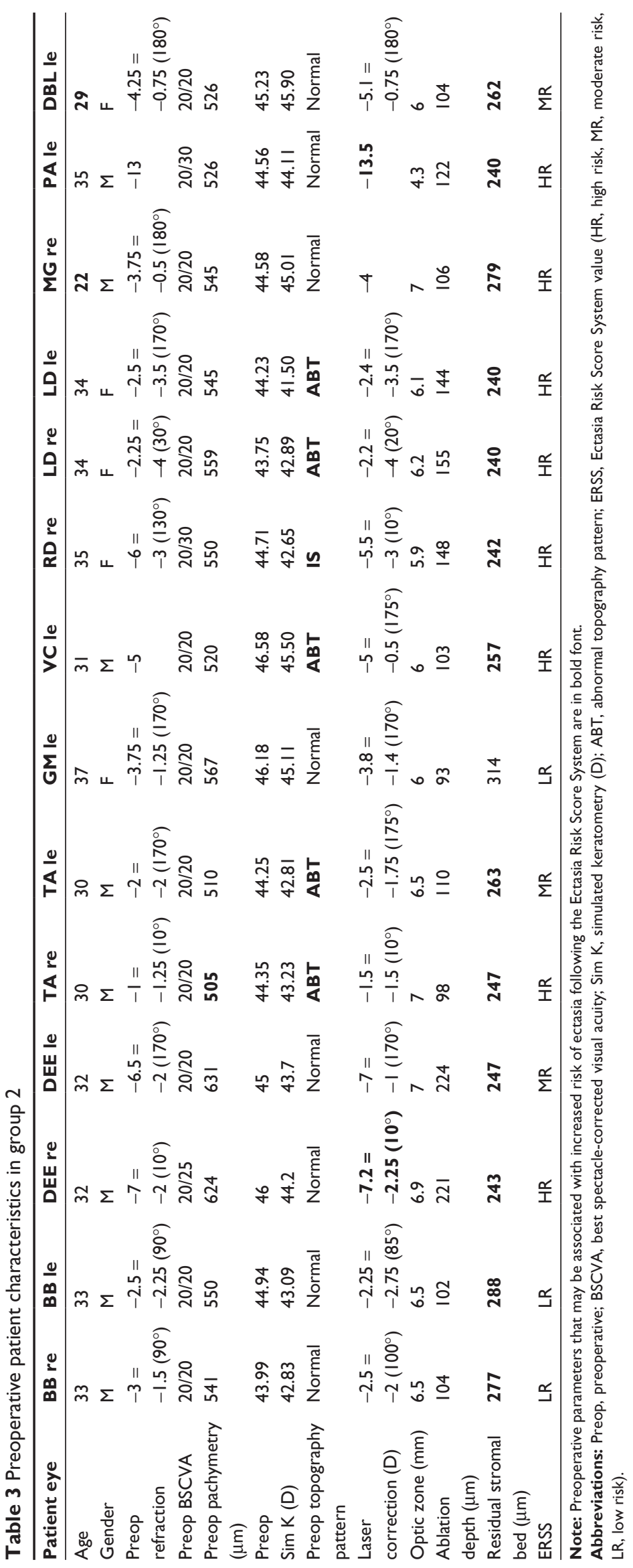


were in the low-risk category. Eight eyes in group 1 were in the high-risk category, none were in the moderate-risk category, and one was in the low-risk category (Table 2), while eight eyes in group 2 were in the high-risk category, three were in the moderate-risk category, and three were in the low-risk category (Table 3 ).

The most important preoperative risk factor in group 1 was manifest refractive spherical equivalent (five eyes with score 4) while a thin residual stromal bed (three eyes with score 3 ) appeared to be in second position followed by abnormal topography (five eyes, including only two eyes with score 3). For group 2, the risks were more diverse, with the most important preoperative risk factor being a thin residual stromal bed (eight eyes with score 3 ), followed by abnormal topography (five eyes with score 1 and one eye with score 3 ), followed by young age (only two eyes).

\section{Discussion}

To our knowledge, this is the first report of the incidence of keratectasia with myopic LASIK from a large number of cases operated by the same surgeon, in the same location, and with extended follow-up. This study attempts to isolate important characteristics contributing to keratectasia by eliminating or controlling for common variables, including type of apparatus and surgical equipment used, surgical technique, and surgeon-specific factors.

In the present study, with its long-term follow-up of a large number of cases, the incidence of corneal ectasia after myopic LASIK was $0.57 \%$, and these data are in agreement with other published data. ${ }^{12}$ The 4027 eyes included were stratified into two groups on the basis of date of surgery and the different surgical equipment used. The incidence of ectasia after LASIK in group 2 was lower than in group $1(0.69 \%$ versus $0.51 \%)$, but this difference was not statistically significant on Chi-square analysis (two-tailed $P$ value $=0.5085)$. This incidence may become lower as a function of time (group 1 patients were operated prior to group 2) given that the patients in group 2 were operated on using newer laser technology and additional care was paid to preoperative patient selection for the procedure.

Post-LASIK ectasia can potentially be avoided by careful patient screening preoperatively to identify risk factors which might lead to this complication. When analyzing our reported cases of corneal ectasia, one should consider that, of the 23 eyes analyzed, 16 were in the high-risk category according to the Ectasia Risk Score System, three eyes were in the moderate-risk category, and four were in the low-risk category (Tables 2 and 3). These results seem to validate the Ectasia Risk Score System proposed by Randleman et al. The present study focused specifically on 23 patients with postoperative corneal ectasia, and excluded analysis of false-positive cases but exhaustively analyzed falsenegative cases. These data would represent a conservative and reasonable approach to preventing the serious complication of iatrogenic ectasia.

It must be considered that the thickness, curvature, shape, and tensile strength of the cornea are modified by surgery. This significantly changes the biomechanical properties of the cornea such that corneas with the same thickness do not necessarily have the same strength. ${ }^{13}$ Histopathological and ultrastructural studies suggest that interlamellar and interfibrillar biomechanical slippage occurs when the cornea becomes ectasic after LASIK in the postoperative stress-bearing regions of the corneal stroma. This two-phase chronic biomechanical failure process is similar to that seen in keratoconus. Composite science classifies this chronic biomechanical failure process as delamination and interfiber fracture. ${ }^{14}$

Thin estimated residual stromal bed thickness was seen in our series in 21 of 23 cases (91.3\%), comprising eight of nine $(88.9 \%)$ in group 1 and 13 of $14(92.8 \%)$ in group 2 . In our experience, the residual stromal bed represents the most important factor in the development of ectasia. The flap cannot act as a barrier against mechanical stress, so iatrogenic keratectasia can easily occur when the remaining stroma is extremely thin, which is a particularly common problem in surgery for high myopes. ${ }^{15}$ After Barraquer insisted that more than $300 \mu \mathrm{m}$ of stroma should be left to prevent iatrogenic keratectasia, surgical equipment has continued to improve. ${ }^{16}$ Therefore, the guideline proposed as the safety margin for residual stroma needs to be changed accordingly. ${ }^{17,18}$

The residual stromal bed thickness is usually calculated as the remainder of the whole corneal thickness minus corneal flap thickness, so is an estimated value. From 1995 to 1999, an estimated residual stromal bed thickness of $200 \mu \mathrm{m}$ was considered by surgeons to be the lower limit. From 1999 to 2002, a residual stromal bed thickness of $250 \mu \mathrm{m}$ was attempted. After 2002, the minimal residual stromal bed thickness was calculated preoperatively to be $300 \mu \mathrm{m}$. If a flap thicker than intended was encountered, the planned laser ablation was reduced by decreasing the intended correction and/or reducing the diameter of the ablation to preserve the residual stromal bed thickness. ${ }^{11}$ 
The literature recommends paying special attention to corneal thickness, amount of thinning, intraocular pressure, type or quality of structural tissue, keratoconus, ocular trauma, and eye size. To ensure that an adequate posterior corneal residual bed is preserved, preoperative corneal thickness and excimer laser ablation depth must be evaluated before LASIK. ${ }^{19}$

Errors in calculation of the residual stromal bed can occur, and can be caused by three factors. The first involves estimating ablation depth as related to the width of the optical zone and the profile of the corneal ablation. Ablation rate per pulse is higher for the middle stroma than for Bowman's layer and the anterior stroma; thus, based on photorefractive keratectomy nomograms, ablation depth in LASIK could be greater than expected..$^{20,21}$ According to more recent experience, refractive surgeons prefer to perform ablations with larger ablation zones to avoid the risks of glare, halos, and postoperative haze. For this reason, attempted correction should rarely exceed the limit of $-12.00 \mathrm{D}$ to $-15.00 \mathrm{D}$. There can also be differences in the degree of laser ablation because the effective level of delivered energy is not always the same..$^{22}$ Moreover, dryness of the cornea during surgery also limits the results. ${ }^{23}$

Second, errors in the calculation of overall corneal thickness with pachymetry can occur, especially in the presence of atypical focal thinner regions not detected by three to four standard measurements over the corneal center. ${ }^{20}$

Another factor could be related to the estimated or real flap thickness, especially using a manually guided microkeratome. Using the ACS Chiron microkeratome with a $160 \mu \mathrm{m}$ plate, flap thickness was reported to be $114.1 \pm 17 \mu \mathrm{m},{ }^{24}$ and $156.0 \pm 26 \mu \mathrm{m}$ with a Schwind microkeratome unit. ${ }^{18}$ Therefore, the value of the estimated residual corneal bed is theoretical, and the real flap thickness is unknown. Using optical coherence tomography after LASIK for high myopia with the Hansatome microkeratome and a $160 \mu \mathrm{m}$ plate, Maldonado et al measured a mean corneal flap thickness of $124.8 \pm 18.5 \mu \mathrm{m}$ one day postoperatively. ${ }^{23}$ Yildrim et al, using the Hansatome microkeratome with a $180 \mu \mathrm{m}$ plate and ultrasound examination reported a mean corneal flap thickness of $120.8 \pm 26.3 \mu \mathrm{m} .{ }^{25}$

Further differences have been reported in creating the corneal flap with a manual or automated microkeratome. ${ }^{26}$ In particular, the cut results are thicker with slower microkeratome advancement, and thinner with faster microkeratome advancement. ${ }^{27}$ Moreover, a manually-guided microkeratome creates a larger flap diameter and increased flap thickness in the direction of the hinge. ${ }^{28}$ In contrast, an automated microkeratome creates a flap that is thinner in the direction of the hinge. For this reason, preoperative and intraoperative measurement of flap thickness using the lower ranges of assumed/calculated residual stromal bed thickness with a given flap creation system could be a good solution to minimize the chances of a thin residual stromal bed.

In the present study, patients in group 1 showed a slightly thicker residual stromal bed than patients in group 2. These data seem contradictory because group 1 patients were treated for higher degrees of myopia. It is possible that in these patients the theoretical (estimated) residual stromal bed does not correspond to the actual stromal bed. We hypothesize that the difference in residual stromal bed may be due to a thicker flap, as shown in one patient who subsequently underwent corneal transplantation where the corneal flap was microscopically measured and found to be $80 \%$ thicker than expected. ${ }^{27}$ To obtain a more realistic evaluation of corneal flap thickness, it would be advisable to perform intraoperative pachymetry. Belin and Ambrosio suggest that, in addition to the intraoperative recommendations made by Binder and Trattler, all preoperative residual stromal bed computations be based on the thinnest preoperative reading. ${ }^{29}$

Even if the flap is made precisely, it is difficult to measure the thickness of stromal bed easily during and after LASIK without expensive devices. There are several corneal imaging devices which are commercially available for measuring residual corneal stromal thickness, such as very high frequency ultrasound, optical coherence tomography, and confocal microscopy. ${ }^{30}$ However, these technologies are often too expensive and are not commonly available in many clinical settings. On the other hand, intraoperative ultrasonic pachymetry is not expensive, but its accuracy is limited by the fact that the exposed stroma is sometimes swollen or the procedure itself can desiccate the stromal bed. ${ }^{31}$

In the present study, patient data are limited to surgeries performed up to 2003, when the risk of post-LASIK ectasia was not widely known and higher corrections were attempted. Therefore, our conclusions do not necessarily apply to current practice. During the period in which these patients underwent surgery, intraoperative measurement of the residual stromal bed thickness was not commonly undertaken, and as such, we calculated the residual stromal bed indirectly using the postoperative total central corneal thickness and the known variable range of flap thickness. Measurement of corneal thickness immediately after surgery is difficult because of the instability of the flap itself. In addition, edema of the cornea after LASIK can lead to faulty measurement of corneal thickness, and this usually normalizes after the fifth 
postoperative day. ${ }^{32}$ The corneal epithelium also has some influence on evaluation of the cornea, becoming thickened between the first and third month postoperatively. ${ }^{33}$ Use of femtosecond laser to achieve a flap with more predictable thickness may be a good substitute tool in this regard. ${ }^{34}$ In addition, increased peripheral wound healing and side-cut architecture enable stronger healing of femtosecond lasercreated flaps compared with mechanical microkeratomes and may be an advantage. ${ }^{35-37}$ There is additional evidence that a strong LASIK wound has the potential to resist deformation from intraocular pressure. ${ }^{38}$

More importance has been given to total residual corneal thickness rather than to stromal bed thickness. The residual bed thickness is the more important parameter for ensuring adequate strength of the corneal tissue, given that the flap has a marginal role in the structural strength of the tissue. As described by Comaish and Lawless, the anterior 100-120 microns of the cornea are stronger than the rest of the stroma and may be more resistant to mechanical deformation than the posterior stroma. ${ }^{39}$ It is evident that because of its collagen structure, some eyes left with a too thin residual corneal thickness after LASIK are unable to withstand normal intraocular pressure and progressive forward forces. The cornea is under constant stress from normal intraocular pressure pushing outward. The collagen bands of the cornea provide its form and biomechanical strength. LASIK thins the cornea and severs collagen bands, permanently weakening the cornea. This results in forward bulging of the cornea. Preclinical ocular pathology such as forme fruste keratoconus and individual differences in corneal tensile strength also make it difficult to determine a safety margin for the stromal bed..$^{18,40}$

Abnormal topographical patterns were seen in our series in eight of 23 cases (34.8\%), comprising two of nine (22.2\%) in group 1 and six of 14 (42.8\%) in group 2. One of the most common findings in ectasia cases has been abnormal preoperative topography, suggesting a pre-existing ectatic corneal disorder, eg, keratoconus, forme fruste keratoconus, or pellucid marginal degeneration. ${ }^{5,8,41,42}$ We assume that an additional risk factor is the removal of a critical amount of corneal tissue from the stromal bed that could structurally weaken the eye. The critical amount of tissue may vary from eye to eye. ${ }^{43}$ In 2003, a review of 85 published cases documented that the majority had abnormal topography prior to LASIK surgery and/or did not undergo intraoperative pachymetry, leaving an unknown assumed residual stromal bed thickness. This literature review was recently updated by Randleman et $\mathrm{al}^{8}$ and Faraj et $\mathrm{al},{ }^{44}$ who suggest that
post-LASIK ectasia in a normal cornea commonly presents as a central steepening, whereas corneas with forme fruste keratoconus are more likely to develop inferior ectasia. Thus, occurrence of inferior ectasia in these patients could suggest preoperative existence of forme fruste keratoconus. Published reports on ectasia have included many eyes with keratoconus or forme fruste keratoconus. If one eliminates eyes with abnormal preoperative topography, that database becomes the basis for comparison with normal eyes, which is what we did in our study. Fifty percent of the preoperative topographical patterns in the validation study by Randleman et al were abnormal. ${ }^{45}$

The literature also advises evaluation of the posterior cornea and avoidance of LASIK when the posterior float is higher than 50 microns centrally because it can be an indicator of keratoconus. ${ }^{46}$ When evaluating the risk of keratectasia, the posterior cornea is an indicative parameter, but in addition to the absolute value of elevation. Another possible risk factor is the site of maximum elevation, which must be at the center of the corneal map. Any decentering, especially if inferior, may be considered to be a risk factor. In most cases, asymmetric topographical maps or inadequate corneal thickness have been underestimated or misunderstood. However, it is important to bear in mind that correct evaluation of the posterior surface of the cornea with Orbscan II depends on many factors, such as corneal transparency and correct acquisition of the image. Patients with normal videokeratoscopy and a negative keratoconus screening by both Klyce/Maeda or Smolek/Klyce analysis may fall two standard deviations outside published norms for elevation and corneal thickness when examined by corneal tomography. ${ }^{47,48}$ The above examples highlight the potential for false-negatives but, as noted, may explain the reason for age being such a significant risk factor in the Ectasia Risk Score System.

Eyes with keratoconus have been noted to have abnormal biomechanical properties, eg, corneal rigidity or resistance factor and corneal hysteresis, both of which can be evaluated using the ocular response analyzer. ${ }^{49}$ This tool has been available for years, and recent reports have outlined its potential as a reliable indicator of abnormal biomechanics in eyes with keratoconus, even for subclinical cases with unremarkable topography. ${ }^{50}$ Galletti et al found that corneal rigidity or resistance, but not corneal hysteresis, could be a reliable indicator of abnormal biomechanics in eyes with keratoconus, even for subclinical cases with unremarkable topography. They have derived both optimized corneal rigidity or resistance cutoff values and transformed 
indices for this purpose, concluding that testing with the ocular response analyzer should be considered in preoperative screening of potential candidates for LASIK.

Currently available corneal tomography techniques include Scheimpflug imaging, optical coherence tomography, and high-frequency ultrasound. Using three-dimensional tomographic reconstruction of the corneal surface and evaluating the posterior corneal surface, with a full pachymetric spatial profile as opposed to just a single central datum point, would change the risk analysis. Currently, pachymetric progression analysis, posterior elevation measurements, and corneal biomechanical testing are the most widely used adjuncts to preoperative screening of potential candidates for LASIK. The present study seems to validate these views. A more complete understanding of the physical and biomechanical properties of the cornea will allow improved determination of an individual's predisposition or susceptibility to developing ectasia. ${ }^{51,52}$

In our series, a large attempted refractive error was seen in eight of 23 ectasia cases (34.8\%), occurring in six of nine $(66.7 \%)$ in group 1 , and two of $14(14.3 \%)$ in group 2. This factor is surely very important in the development of post-LASIK ectasia. ${ }^{53}$ However, asymmetric refraction between the two fellow eyes was also important. In fact, if asymmetry is noted in the preoperative refraction, in which the corrected vision in one eye is one or two lines less than in the fellow eye, one must be concerned about the presence of an abnormality in that visual system. An asymmetry in the manifest refraction of more than $1 \mathrm{D}$, significant asymmetry in topography, and a significant difference between the location of the corneal apex and the thinnest point in the cornea should increase the suspicion of an abnormality in the cornea, even in the absence of a positive family history. A family history of an ectatic corneal disorder in the absence of any clinical findings warrants consideration of a form of vision correction other than LASIK. ${ }^{54}$

An additional risk factor may be related to the shape and depth of an individual laser ablation. Previous laser ablation profiles are substantially different from current wavefront-guided algorithms, which may be less structurally destabilizing because they can potentially remove less tissue per diopter of attempted correction. ${ }^{55}$

Young patient age was noted in our series in four of 23 cases $(17.4 \%)$, comprising two of nine (22.2\%) in group 1 and two of $14(14.3 \%)$ in group 2. Binder and Trattler analyzed about 150 eyes from patients aged 21-29 years, with a follow-up ranging from 24.9 to 27.9 months, and none of these eyes developed ectasia. ${ }^{11}$ Much of the criticism of the
Ectasia Risk Score System strategy relates to the high risk score assigned to patient age. Keratoconus is a disease that typically presents in the late teens and/or twenties. A truly new noniatrogenic case of keratoconus presenting past the fourth decade is rare. If we were able to identify early disease with $100 \%$ specificity and sensitivity, age would likely be of much less concern.

Small preoperative central corneal thicknesses were also seen in our series in four of 23 cases (17.4\%), comprising three of nine $(33.3 \%)$ in group 1 and one of $14(0.7 \%)$ in group 2. Thin corneas with normal topographies have been considered by some surgeons to be a risk factor for developing ectasia. ${ }^{5,7,8,45,56}$ However, studies of eyes undergoing LASIK with corneal thicknesses less than $500 \mu \mathrm{m}$ and normal preoperative topographies did not develop ectasia., 2,57,58

Other genetic or molecular factors, at present nonidentifiable, may be important for the development of ectasia. Lambiase et al recently described the absence of nerve growth factor receptor in 10 patients with advanced keratoconus, and hypothesized this to be a possible pathogenetic factor for development of corneal dystrophy. ${ }^{59}$ In contrast, nerve growth factor receptor was reported to be present in two cases of keratoconus induced by refractive surgery. No refractive data for these two cases were reported, but it is reasonable to assume that those cases had identifiable risk factors (eg, high treated myopia). In fact, the patients undergoing penetrating keratoplasty in that study were comparable with most of our patients in group 1. It would be interesting to investigate the presence/absence of nerve growth factor receptor in patients with post-LASIK ectasia and nonidentifiable risk factors, and also in a larger number of patients.

Management of iatrogenic keratectasia consists of penetrating keratoplasty and, more recently, lamellar keratoplasty. ${ }^{60}$ The principle common to all lamellar keratoplasty techniques is selective removal of pathological tissue only and sparing of the deeper corneal layers (Descemet's membrane and endothelium) and restoring normal corneal thickness by implanting a lamellar graft. However, hand dissection is a difficult, painstaking procedure that is rarely as precise as required. To circumvent these problems, some surgeons are now using an excimer laser to remove the recipient corneal stroma, leaving a good quality stromal bed surface. ${ }^{61}$ Therefore, customized excimer laser-assisted lamellar keratoplasty has been conceived as a valuable alternative to penetrating keratoplasty for the treatment of keratoconus and keratectasia. ${ }^{62}$ However, we recently reported a case of a patient with corneal ectasia which developed after excimer 
laser-assisted lamellar keratoplasty for keratoconus and a secondary photorefractive keratectomy for residual refractive error where the treatment of collagen corneal cross-linking with riboflavin and ultraviolet A (CXL) provided safe and effective management of the ectasia. ${ }^{63}$ In fact, with the success observed for CXL in the treatment of progressive keratoconus, some studies have reported on the use of CXL for postoperative keratectasia in very thin corneas. ${ }^{64}$

In conclusion, our investigation of the long-term outcome in a large number of patients indicates that the incidence of corneal ectasia after myopic LASIK is low. Moreover, the Ectasia Risk Score System devised by Randleman et al may be considered a good step towards understanding the critical variables present in eyes that have developed postoperative LASIK ectasia.

\section{Acknowledgments}

This research was supported financially by the Department of Biotechnological and Applied Clinical Sciences, University of L'Aquila, L'Aquila, Italy.

\section{Disclosure}

The authors report no conflicts of interest in this work.

\section{References}

1. Randleman JB. Post-laser in-situ keratomileusis ectasia: current understanding and future directions. Curr Opin Ophthalmol. 2006; 17:406-412.

2. Binder PS. Analysis of ectasia after laser in situ keratomileusis: risk factors. J Cataract Refract Surg. 2007;33:1530-1538.

3. Chen MC, Lee N, Bourla N, Hamilton DR. Corneal biomechanical measurements before and after laser in situ keratomileusis. J Cataract Refract Surg. 2008;34:1886-1891.

4. Kirwan C, O’Malley D, O'Keefe M. Corneal hysteresis and corneal resistance factor in keratectasia: finding using the Reichert ocular response analyzer. Ophtalmologica. 2008;222:334-337.

5. Randleman JB, Russell B, Ward MA, Thompson KP, Stulting RD. Risk factors and prognosis for corneal ectasia after LASIK. Ophthalmology. 2003;110:267-275.

6. Rabinowitz YS. Ectasia after laser in situ keratomileusis. Curr Opin Ophthalmol. 2006;17:421-426.

7. Klein SR, Epstein RJ, Randleman JB, Stulting RD. Corneal ectasia after laser in situ keratomileusis in patients without apparent preoperative risk factors. Cornea. 2006;25:388-403.

8. Randleman JB, Woodward M, Lynn MJ, Stulting RD. Risk assessment for ectasia after corneal refractive surgery. Ophthalmology. 2008;115:37-50.

9. Chan CC, Hodge C, Sutton G. External analysis of the Randleman Ectasia Risk Factor score system: a review of 36 cases of post LASIK ectasia. Clin Experiment Ophthalmol. 2010;38:335-340.

10. Ambrósio R Jr, Dawson DG, Salomão M, Guerra FP, Caiado AL, Belin MW. Corneal ectasia after LASIK despite low preoperative risk: tomographic and biomechanical findings in the unoperated, stable, fellow eye. J Refract Surg. 2010;26:906-911.

11. Binder PS, Trattler WB. Evaluation of a risk factor scoring system for corneal ectasia after LASIK in eyes with normal topography. J Refract Surg. 2010;26:241-250.
12. Twa MD, Nichols JJ, Joslin, et al. Characteristics of corneal ectasia after LASIK for myopia. Cornea. 2004;23:447-457.

13. Piccoli PM, Gomes AAC, Piccoli FVR. Corneal ectasia detected 32 months after LASIK for correction of myopia and asymmetric astigmatism. J Cataract Refract Surg. 2003;29:1222-1225.

14. Dawson DG, Randleman JB, Grossniklaus HE, et al. Corneal ectasia after excimer laser keratorefractive surgery: histopathology, ultrastructure, and pathophysiology. Ophthalmology. 2008;115: 2181-2191.

15. Seiler T, Koufala K, Richter G. Iatrogenic keratectasia after laser in situ keratomileusis. J Refract Surg. 1998;14:312-317.

16. Barraquer JI. Keratomileusis for myopia and aphakia. Ophthalmology. 1981;88:701-708

17. Andreassen T, Simonsen TH, Oxlund H. Biomechanical properties of keratoconus and normal corneas. Exp Eye Res. 1980;31:435-441.

18. Seiler T, Quurke AW. Iatrogenic keratectasia after LASIK in a case of forme fruste keratoconus. J Cataract Refract Surg. 1998;24: $1007-1009$.

19. Pallikaris IG, Kymionis GD, Astyrakakis NI. Corneal ectasia induced by laser in situ keratomileusis. J Cataract Refract Surg. 2001;27: 1796-1802.

20. Koch DD. The riddle of iatrogenic keratectasia. $J$ Cataract Refract Surg. 1999;25:453-454.

21. Wang Z, Chen J, Yang B. Posterior corneal surface topographic changes after laser in situ keratomileusis are related to residual corneal bed thickness. Ophthalmology. 1999;106:406-410.

22. Lee DH, Kwon OY, Kim JM. The comparison of corneal ablation amount by MEL-60 excimer laser and Schwind Multiscan excimer laser systems. J Korean Ophthalmol Soc. 2003;44:1048-1053.

23. Maldonado MJ,Ruiz-Oblitas L, Munuera JM,Aliseda D, Garcia-LayanaA, Moreno-Montanes J. Optical coherence tomography evaluation of the corneal cap and stromal bed features after laser in situ keratomileusis for high myopia and astigmatism. Ophthalmology. 2000;107:81-88.

24. Pérez-Santonja JJ, Bellot J, Claramonte P, Ismail MM, Alió JL. Laser in situ keratomileusis to correct high myopia. $J$ Cataract Refract Surg. 1997;23:372-385.

25. Yildrim R, Aras C, Ozdamar A, Bahcecioglu H, Ozkan S. Reproducibility of corneal flap thickness in laser in situ keratomileusis using the Hansatome microkeratome. J Cataract Refract Surg. 2000;26: $1729-1732$.

26. Reinstein DZ, Silverman RH, Raevsky T, et al. Arc-scanning very high frequency digital ultrasound for 3D pachymetric mapping of the corneal epithelium end stroma in laser in situ keratomileusis. J Refract Surg. 2000;16:414-430

27. Spadea L, Palmieri G, Mosca L, Fasciani R, Balestrazzi E. Iatrogenic keratectasia following laser in situ keratomileusis. J Refract Surg. 2002;18:475-480.

28. Behrens A, Seitz B, Langenbucher A, Kus MM, Rummelt C, Küchle M. Evaluation of corneal flap dimensions and cut quality using a manually guided microkeratome. J Refract Surg. 1999;15:118-123.

29. Belin MW, Ambrósio R Jr. Corneal ectasia risk score: statistical validity and clinical relevance. $J$ Refract Surg. 2010;26:238-240.

30. Wirbelauer C, Pham DT. Monitoring corneal structures with slitlamp adapted optical coherence tomography in laser in situ keratomileusis. $J$ Cataract Refract Surg. 2004;30:1851-1860

31. Dayanir V, Sakarya R, Ozcura F, et al. Effect of corneal drying on central corneal thickness. J Glaucoma. 2004;13:6-8.

32. Feltham MH, Stapleton F. Change in central corneal thickness following laser in situ keratomileusis for myopia. Clin Experiment Ophthalmol. 2000;28:185-187.

33. Spadea L, Fasciani R, Necozione S, Balestrazzi E. Role of the corneal epithelium in refractive changes following laser in situ keratomileusis for high myopia. J Refract Surg. 2000;16:133-139.

34. Ratkay-Traub I, Ferincz IE, Juhasz T, Kurtz RM, Krueger RR. First clinical results with the femtosecond neodynium-glass laser in refractive surgery. J Refract Surg. 2003;19:94-103. 
35. Netto MV, Mohan RR, Medeiros F, et al. Femtosecond laser and microkeratome corneal flaps: comparison of stromal wound healing and inflammation. J Refract Surg. 2007;23:667-676.

36. Dawson DG, Grossniklaus HE, McCarey BE, Edelhauser HF. Biomechanical and wound healing characteristics of corneas after excimer laser keratorefractive surgery: is there a difference between advanced surface ablation and sub-Bowman's keratomileusis? J Refract Surg. 2008;24:S90-S96.

37. Knorz MC, Vossmerbaeumer U. Comparison of flap adhesion strength using the Amadeus microkeratome and the IntraLase iFS femtosecond laser in rabbits. J Refract Surg. 2008;24:875-878.

38. Abdelkader A, Esquenazi S, Shihadeh W, et al. Healing process at the flap edge in its influence in the development of corneal ectasia after LASIK. Curr Eye Res. 2006;31:903-908.

39. Comaish IF, Lawless MA. Progressive post-LASIK keratectasia: biomechanical instability or chronic disease process? J Cataract Refract Surg. 2002;28:2206-2213.

40. Wang JC, Hufnagel TJ, Buxton DF. Bilateral keratectasia after unilateral laser in situ keratomileusis: a retrospective diagnosis of ectatic corneal disorder. J Cataract Refract Surg. 2003;29:2015-2018.

41. Binder PS. Ectasia after laser in situ keratomileusis. J Cataract Refract Surg. 2003;29:2419-2429.

42. Binder PS, Lindstrom RL, Stulting RD, et al. Keratoconus and corneal ectasia after LASIK. J Cataract Refract Surg. 2005;31:2035-2038.

43. Smolek MK, McCarey BE. Interlamellar cohesive strength in human eyebank corneas. Invest Ophthalmol Vis Sci. 1990;31:1087-1095.

44. Faraj HG, Gatinel D, Chastang PJ, Hoang-Xuan T. Corneal ectasia after LASIK. ASCRS and ESCRS 2003 correction of myopia and asymmetric astigmatism. J Cataract Refract Surg. 2003;29: $1222-1225$.

45. Randleman JB, Trattler WB, Stulting RD. Validation of the Ectasia Risk Score System for preoperative laser in situ keratomileusis screening. Am J Ophthalmol. 2008;145:813-818.

46. Rao SN, Raviv T, Majmudar PA, Epstein RJ. Role of Orbscan II in screening keratoconus suspects before refractive corneal surgery. Ophthalmology. 2002;109:1642-1646.

47. Khachikian SS, Belin MW. Posterior elevation in keratoconus. Ophthalmology. 2009;116:816-817.

48. Ambrósio R Jr, Alonso RS, Luz A, Coca Velarde LG. Corneal thickness spatial profile and corneal-volume distribution: tomographic indices to detect keratoconus. J Cataract Refract Surg. 2006;32:1851-1859.

49. Luce DA. Determining in vivo biomechanical properties of the cornea with an ocular response analyzer. J Cataract Refract Surg. 2005;31: $156-162$
50. Galletti JG, Pförtner T, Bonthoux FF. Improved keratoconus detection by ocular response analyzer testing after consideration of corneal thickness as a confounding factor. J Refract Surg. 2012;28:202-208.

51. Belin MW, Khachikian SS. An introduction to understanding elevationbased topography: how elevation data are displayed - a review. Clin Experiment Ophthalmol. 2009;37:14-29.

52. Belin MW, Khachikian SS. New devices and clinical implications for measuring corneal thickness. Clin Experiment Ophthalmol. 2006;34:729-731.

53. Condon PI, O'Keefe M, Binder PS. Long-term results of laser in situ keratomileusis for high myopia: Risk for ectasia. J Cataract Refract Surg. 2007;33:583-590.

54. Binder PS, Lindstrom RL, Stulting RD, et al. Keratoconus and corneal ectasia after LASIK. J Cataract Refract Surg. 2005;31:2035-2038.

55. Vinciguerra P, Munoz MI, Camesasca FI, Grizzi F, Roberts C. Longterm follow-up of ultrathin corneas after surface retreatment with phototherapeutic keratectomy. J Cataract Refract Surg. 2005;31:82-87.

56. Amoils S, Deist M, Gous P, Amoils PM. Iatrogenic keratectasia after laser in situ keratomileusis for less than -4.0 to -7.0 diopters of myopia. $J$ Cataract Refract Surg. 2000;26:967-977.

57. Kymionis GD, Bouzoukis D, Diakonis V, et al. Long-term results of thin corneas after refractive laser surgery. Am J Ophthalmol. 2007;144: 181-185.

58. Caster AI, Friess DW, Potvin RJ. Absence of kerectasia after LASIK in eyes with preoperative central corneal thickness of 450 to 500 microns. J Refract Surg. 2007;23:782-788.

59. Lambiase A, Merlo D, Collinari C, et al. Molecular basis for keratoconus: Lack of TrkA expression and its transcriptional repression by Sp3. Proc Natl Acad Sci U S A. 2005;102:16795-16800.

60. Kucumen RB, Yenerel NM, Gorgun E, Oncel M. Penetrating keratoplasty for corneal ectasia after laser in situ keratomileusis. Eur $J$ Ophthalmol. 2008;18:695-702.

61. Spadea L, Giammaria D, Fiasca A, Verrecchia V. Excimer laser-assisted lamellar keratoplasty for the surgical treatment of keratoconus. J Cataract Refract Surg. 2009;35:105-112.

62. Spadea L, Gizzi R, Evangelista Conocchia N, Urbano S. Optical pachimetry-guided customized excimer laser-assisted lamellar keratoplasty for the surgical treatment of keratoconus. J Cataract Refract Surg. 2012;38:1559-1567.

63. Spadea L. Collagen crosslinking for ectasia following PRK performed in excimer laser-assisted keratoplasty for keratoconus. Eur J Ophthalmol. 2012;22:274-277.

64. Spadea L, Mencucci R. Transepithelial corneal collagen cross-linking in ultrathin keratoconic corneas. Clin Ophthalmol. 2012;6:1785-1792.
Clinical Ophthalmology

\section{Publish your work in this journal}

Clinical Ophthalmology is an international, peer-reviewed journal covering all subspecialties within ophthalmology. Key topics include: Optometry; Visual science; Pharmacology and drug therapy in eye diseases; Basic Sciences; Primary and Secondary eye care; Patient Safety and Quality of Care Improvements. This journal is indexed on

\section{Dovepress}

PubMed Central and CAS, and is the official journal of The Society of Clinical Ophthalmology (SCO). The manuscript management system is completely online and includes a very quick and fair peer-review system, which is all easy to use. Visit http://www.dovepress.com/ testimonials.php to read real quotes from published authors. 